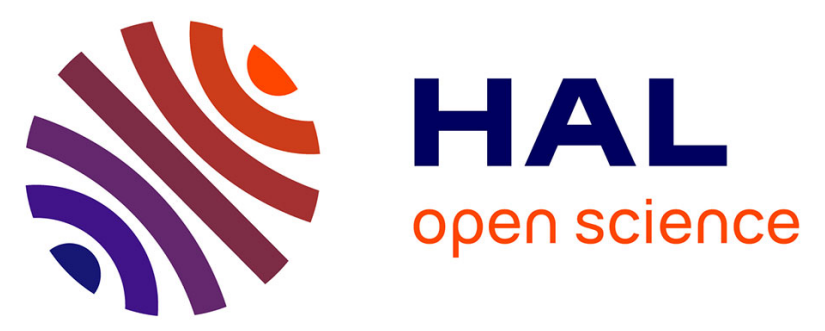

\title{
Age-related changes in controllable and uncontrollable processes underlying evaluative conditioning: a comparison between children ages 7 to 11 and young adults
}

Laurent Waroquier, Marlène Abadie, Agnès Blaye

\section{To cite this version:}

Laurent Waroquier, Marlène Abadie, Agnès Blaye. Age-related changes in controllable and uncontrollable processes underlying evaluative conditioning: a comparison between children ages 7 to 11 and young adults. Developmental Psychology, In press. hal-03376383v2

\section{HAL Id: hal-03376383 \\ https://hal.science/hal-03376383v2}

Submitted on 8 Nov 2021

HAL is a multi-disciplinary open access archive for the deposit and dissemination of scientific research documents, whether they are published or not. The documents may come from teaching and research institutions in France or abroad, or from public or private research centers.
L'archive ouverte pluridisciplinaire HAL, est destinée au dépôt et à la diffusion de documents scientifiques de niveau recherche, publiés ou non, émanant des établissements d'enseignement et de recherche français ou étrangers, des laboratoires publics ou privés. 
Running title: Age-related changes in EC controllability

In press, 2021, Developmental Psychology

This paper is not the copy of record and may not exactly replicate the final, authoritative version of the article. Please do not copy or cite without authors' permission. The final article will be available, upon publication.

Age-related changes in controllable and uncontrollable processes underlying evaluative conditioning: a comparison between children ages 7 to 11 and young adults

Laurent Waroquier ${ }^{1}$, Marlène Abadie ${ }^{2}$, \& Agnès Blaye ${ }^{2}$

\section{Author Note}

${ }^{1}$ Laurent Waroquier, Université Clermont Auvergne, CNRS, LAPSCO, F-63000 ClermontFerrand, France. ${ }^{2}$ Marlène Abadie, marlene.ABADIE@ univ-amu.fr, \& Agnès Blaye, agnes.blaye@univ-amu.fr, Laboratoire de Psychologie Cognitive, Aix-Marseille Université, France. Correspondence concerning this article should be addressed to Laurent Waroquier, Laboratoire de Psychologie Sociale et Cognitive, 34 avenue Carnot - TSA 60401- 63001 Clermont-Ferrand Cedex 1, France, https://orcid.org/0000-0001-5479-9100, laurent.waroquier@uca.fr, +33 (0) 473406366.

The experiment was not formally preregistered. The exact instructions given to participants, CS, US International Affective Picture System (Lang et al., 2008) number and the data are available on Open Science Framework (https://osf.io/8yskg/?view_only=67a3ad2a41b54b5e8f3e43d6685f3676). 


\begin{abstract}
Evaluative conditioning (EC) refers to a change in liking of a conditioned stimulus (CS) consecutive to its repeated pairing with a valent unconditioned stimulus (US). We relied on a multinomial processing tree model to compare the processes underlying EC in middle-aged children $\left(n=57 ; M_{\text {age }}=8.65 ;\right.$ range $=6.94-11.03 ; 31$ females $)$ and young adults $(n=57$; $M_{\text {age }}=19.16 ;$ range $=17.60-23.60 ; 53$ females $)$. We found that controllable and uncontrollable valence transfer processes concurrently contributed to EC in adults and provided initial evidence that they are already present in children. Moreover, the experiment revealed that both types of processes are weaker in children than in adults and that controllable processes are stronger in older children than in younger ones. These findings suggest that both controllable and uncontrollable processes already underlie EC in middleaged children but that they continue to mature after childhood.
\end{abstract}

Keywords: attitude formation, evaluative conditioning, automaticity, cognitive control, multinomial processing tree models, cognitive development 
Whether on billboards or via various screens, children are constantly the target of attempts to influence them consistent with the principle of evaluative conditioning (EC). EC procedures consist in repeatedly pairing a conditioned stimulus (CS) with an unconditioned stimulus (US) of either positive or negative valence. As a result, attitudes (i.e., our likes and dislikes) become more positive toward positively paired CS and more negative toward negatively paired ones, a phenomenon known as the EC effect (De Houwer, 2007).

The EC effect has been replicated many times with adult participants (see Hofmann, et al., 2010, for a meta-analysis). In contrast, only a few studies have investigated it in children. While a couple of studies showed EC effects in 3 to 6 years old (Halbeisen et al., 2017, 2020) and 7 to 11 years old children (Beckers et al., 2009; Field, 2006), EC is weaker in children (Hofmann et al., 2010) and some studies even found no EC effect in children (e.g., Charlesworth et al., 2020). This lack of investigations is surprising, as many attitudes are acquired during childhood (Rutland et al., 2005). Furthermore, a couple of recent studies, conducted in adults, examined whether the impact of the pairings on evaluative responses can be intentionally controlled (e.g., minimized or maximized) and whether the acquisition of conditioned attitude occurs via controllable or uncontrollable valence transfer processes (Balas \& Gawronski, 2012; Gawronski et al., 2014, Gawronski et al., 2015; Hütter \& Sweldens, 2018). However, these questions had not yet been studied in children. The present study was the first to investigate the cognitive processes underlying EC in children. More specifically, as cognitive control is still immature in children (Chevalier \& Blaye, in press), we compared the role of controllable and uncontrollable valence transfer processes in middleaged children and young adults.

The demonstration that EC procedures can have some uncontrollable effects on attitudes of children would have important practical and ethical implications. EC may indeed lead to the acquisition of attitudes that can have significant consequences in domains such as 
racial prejudice (e.g., Olson \& Fazio, 2006), health (e.g., Hollands et al., 2011), or consumption (e.g., Stuart et al., 1987). From a theoretical point of view, the controllability question is related to the general debate about the implication of automatic processes in learning in general and in attitudes acquisition in particular (Mitchell et al., 2009; McLaren, et al., 2014). According to single-process models of attitude learning, valence transfer from US to CS is exclusively mediated by conscious propositions about how the two stimuli are related whereas dual-process models posit that valence transfer may also occur automatically via the mere registration of the co-occurrences between stimuli (e.g., Gawronski \& Bodenhausen, 2014). Conscious propositions give rise to an intentional and controllable transfer of valence because it can be modulated by information about the relation between stimuli. For example, the information that disinfectant prevents wounds from becoming infected should lead to a positive attitude toward disinfectant and should override potential negative attitude that may result from repeated co-occurrences of the disinfectant and getting injured. By contrast, one of the features of automatic processes is uncontrollability (e.g., US valence is transferred to CS irrespective of people intentions to be or not to be influenced by stimuli co-occurrences), the other three being unawareness, efficiency (i.e., they operate with few attentional resources) and goal independence (Bargh, 1992). While the other features of automaticity have been studied more extensively (e.g., Waroquier et al., 2020; see Corneille \& Stahl, 2018; Sweldens et al., 2014 for reviews), it is only recently that a few EC studies have examined the controllability question in adults. These studies suggest that even in adults, the impact of the pairings is only partially controllable. Indeed, most recent studies suggest that independent controllable and uncontrollable processes lead to valence transfer in the same EC procedure (Hütter \& Sweldens, 2018).

The present study is the first to address the controllability question in children. Controllable valence transfer processes are likely to develop in parallel with more general 
cognitive control abilities. Cognitive control refers to the ability to regulate behavior to produce a goal-directed response in a situation that cannot be resolved automatically (Miller \& Cohen, 2001). As it involves brain structures that mature particularly slowly (including prefrontal, anterior cingulate and parietal cortices) it follows a protracted development (Sera \& Scott, 2013; Zelazo \& Carlson, 2012). Furthermore, it plays a key role in explicit learning (Chevalier \& Blaye, in press).The literature on the development of cognitive control showed that control may be triggered intentionally, guided by a cue that explicitly signals what is required or incidentally as function of experience learned in the task and that the two forms of control develop differently (Gonthier et al., 2021). In the present study, we focused on the first form of control as participants were provided with explicit instructions on how to respond to stimuli. The study therefore involved children from 7 years as they are able to engage cognitive control in response to explicit cues given in advance (Chevalier \& Blaye, in press). Major qualitative changes in intentional cognitive control occur somewhat earlier in preschoolers (Chevalier, 2015; Zanolie \& Crone, 2018). More specifically, the use of proactive control emerges around age 5-6 (e.g., Gonthier et al., 2019). After the age of 7, the changes are slower and mostly quantitative and these improvements continue until early adulthood (e.g., Lorsbach \& Reimer, 2008). Hence, we compared controllable attitude learning processes in children aged 7 to 11 years and in adults.

Recent studies showed that, in adults, valence transfer may also occur via processes that are uncontrollable, efficient and goal-independent (Hütter \& Sweldens, 2018; see also Corneille et al., 2019). Processes that are characterized by several features of automaticity may thus underlie EC in adults (e.g., Hütter et al., 2012; Hütter \& Sweldens, 2018; contrast Corneille \& Stahl, 2019). Not all automatic processes have the same developmental trajectory. On the one hand, some automatic processes may be acquired in very early childhood or even be innate (Bargh et al., 2012; Spelke \& Kinzle, 2007). For example, pre- 
attentive processes involved in the coding of simple physical features such as color, size, and shape orientation, are innate and apparently insensitive to learning (Treisman et al., 1992). On the other hand, automaticity may result from skills acquisition (Cleeremans \& Jiménez, 2002; Tzelgov, 1997). Indeed, the degree of automaticity with which children solve a variety of cognitive tasks such as visual and memory search, mental rotation and mental addition increases with age (Kail, 1988). Moreover, studies on the development of automatic associative processes in memory and false memory suggest that they increase at least until the age of 11 years (e.g., Wimmer \& Howe, 2009). The current study will explore whether uncontrollable valence transfer processes involved in EC are already fully functional in children or continue to develop between middle childhood and adulthood.

In order, to investigate the processes underlying attitude acquisition in children we adapted the multinomial processing tree model recently developed by Hütter and Sweldens (2018). Contrary to previous approaches, this model allows quantifying controllable and uncontrollable valence transfer processes in a single explicit dichotomous evaluation measure (i.e., pleasant vs. unpleasant). Following the logic of the process dissociation procedure (Jacoby, 1991), a variant of the EC procedure in which controllable and uncontrollable processes act in concert and another one in which they oppose each other were used. In the standard instructions condition, participants were told that US valence gives information concerning CS pleasantness while in the reversal instructions condition they were told that it gives false information (i.e., pleasant CS are paired with unpleasant US and vice versa). Thus, both controllable and uncontrollable valence transfer processes should lead to evaluate CS in line with US valence for standard instructions. By contrast, for reversal instructions, controllable processes should lead to evaluate CS oppositely to US valence and uncontrollable ones to evaluate them in line with it. Based on participants' responses in the two variants of the task, three parameters can be estimated. The $c$-parameter is an estimate of the percentage 
of trials where valence transfer occurs through controllable processes. Among trials for which control failed (1-c), the $u$-parameter is an estimate of the percentage of trials where valence transfer occurs through uncontrollable processes. Among trials in which there is no valence transfer $[(1-c) *(1-u)]$, the $r$-parameter reflects the proportion of positive responses based on non-systematic processes (see Hütter \& Sweldens, 2018, for a processing tree representation).

Children aged 7 to 11 and young adults were exposed to a conditioning procedure adapted from the paradigm developed by Hütter and Sweldens. To make the paradigm suitable for both children and adults we have shortened the procedure, adapted the instructions as well as the stimuli. Based on previous research, we expected a regular EC effect for standard instructions and a reversed EC effect for reversal instructions. As average EC effect size was smaller in children in previous research (Hofmann et al., 2010), we also expected that these effects would be smaller in children than in adults. More importantly, we hypothesized that both controllable and uncontrollable processes would underlie valence transfer in children and in adults. We also expected that controllable processes would be weaker in children than in adults. Two competing hypotheses can be formulated regarding the comparison of the strength of uncontrollable processes in adults and in children. They could be weaker in children if these processes are still immature or of equal strength if they are already fully functional.

\section{Method}

The experiment was not formally preregistered. The exact instructions given to participants, CS, US International Affective Picture System (Lang et al., 2008) number and the data are available on Open Science Framework (https://osf.io/8yskg/?view_only=67a3ad2a41b54b5e8f3e43d6685f3676). 


\section{Participants and design}

A power analysis for hypothesis tests on the $c$ - and $u$ - parameters is reported in Table 1. This analysis revealed we had a statistical power of .95 or higher for most hypothesis tests and a power of .68 to detect a difference between the $u$-parameter and zero in children.

Fifty seven Aix-Marseille University students $\left(\operatorname{Min}_{\text {age }}=17.60 ;\right.$ Max $_{\text {age }}=23.60 ; M_{\text {age }}=$ 19.16; $S D_{\text {age }}=0.97 ; 53$ females) and fifty seven children who completed the experiment in an elementary school in Aix-en-Provence $(n=53)$ or at home $(n=4)$ took part in the experiment $\left(\right.$ Min $_{\text {age }}=6.94 ;$ Max $_{\text {age }}=11.03 ; M_{\text {age }}=8.65 ; S D_{\text {age }}=1.00 ; 31$ females $)$. The data from one additional university student were excluded from all analyses because he failed to comply with instructions. Written informed consent was obtained from participants or their parents. University students received course credits in return for their participation. The study conformed to the ethical standards of the declaration of Helsinki and was approved by the ethic committee of Aix-Marseille University ('Etude des processus contrôlables et incontrôlables sous-tendant le conditionnement évaluatif', protocol number: 2021-01-07-09). The design of the study included US valence (positive vs. negative) and time of measurement (preratings vs. postratings) as within-subjects factors and instruction condition (standard vs. reversal) and age group (children vs. young adult) as between-subjects factors.

Insert Table 1 about here

\section{Procedure}


All participants completed the experiment individually on a computer, in a quiet room, under the supervision of an experimenter present to read instructions and ensure attention. Participants started the experiment by evaluating a set of 12 pleasant and 12 unpleasant pictures from the IAPS on a 7 point smiley rating scale ranging from very unpleasant to very pleasant. These pictures were suitable for children of 7 years and older ${ }^{1}$. The 6 most pleasant and the 6 most unpleasant pictures for each participant were selected as positive and negative US. Participants then evaluated a set of 24 black-and-white pictures of human faces (12 females, 12 males), that had already been used in previous research (Waroquier et al., 2020; Lundqvist et al., 1998), on a 7 point smiley rating scale. For each participant, the 12 faces with the most neutral rating were selected as CS.

Prior to the conditioning phase participants received standard or reversal instructions. In both conditions they were told that they would see faces of unknown persons and that pictures would be presented at the same time. In the standard condition they were told that these pictures provide information about people and that when a face is presented with a pleasant picture it means that the person is pleasant while when it is presented with an unpleasant picture it means that the person is unpleasant. In the reversal condition, they were told that pictures give false information about people and that when a face is presented with a pleasant picture it means that the person is unpleasant while when it is presented with an unpleasant picture it means that the person is pleasant. In the subsequent conditioning phase, each CS was randomly assigned to a US. Each pair was presented 6 times in a simultaneous presentation. CS were displayed to the right of the US during half of the presentations and to the left during the other half. Pairings were presented in a random order for 2,500 $\mathrm{ms}$ with an inter-trial interval of $500 \mathrm{~ms}$. After the conditioning phase participants first evaluated each CS on a dichotomous rating scale (pleasant vs. unpleasant). These dichotomous evaluative responses are needed to estimate the model parameters. Next, they evaluated CS on a 7 point 
smiley rating scale which is a more common measure of attitude. At the end of the experiment, participants were thanked and debriefed. Prior to taking part in the actual experiment, participants had carried out a training phase in which they had familiarized themselves with the standard or the reversal instructions (depending on the condition), the conditioning procedure and the dichotomous and 7 point smiley rating scales that were used in the actual experiment. During the training, participants performed a short version of the EC task during which the experimenter gave a feedback after each CS evaluation. Before they started the actual experiment, the experimenter made sure that each participant was able to explain what he had to do in their own words. Pictures used during the training phase were not used in the actual experiment.

\section{Results}

We first analyzed evaluative ratings in order to assess EC effects and compared EC effects obtained in children and in adults. Next, we analyzed response frequencies at the dichotomous evaluation task in order to estimate controllable and uncontrollable valence transfer processes and compared the processes estimates in children and in adults.

\section{Evaluative ratings}

CS evaluative ratings are displayed in Figure 1 for the two instruction conditions and the two age groups. They were submitted to a 2 (US valence) $\times 2$ (time of measurement) $\times 2$ (instruction condition) x 2 (age group: children vs. adults) mixed ANOVA. This analysis revealed an overall EC effect as evidenced by a significant interaction between US valence and time of measurement, $F(1,110)=25.6, p<.001, \eta_{\mathrm{p}}{ }^{2}=.189,90 \%$ CI $[.089, .29]^{2}$. Importantly, the EC effect was moderated by instruction condition, $F(1,110)=64.8, p<.001$, $\eta_{\mathrm{p}}{ }^{2}=.371,90 \% \mathrm{CI}[.25, .47]$, and the four-way interaction between US valence, time of 
measurement, instruction condition and age group was significant, $F(1,110)=5.84, p=.017$, $\eta_{\mathrm{p}}{ }^{2}=.05,90 \%$ CI $[.005, .13]$. Additionally, the main effect of US valence, $F(1,110)=21.1$, $p<.001, \eta_{\mathrm{p}}^{2}=.161,90 \% \mathrm{CI}[.068, .26]$, the interaction between US valence and instruction condition, $F(1,110)=57.9, p<.001, \eta_{\mathrm{p}}^{2}=.345,90 \% \mathrm{CI}[.23, .44]$, the interaction between US valence and age group, $F(1,110)=4.25, p=.041, \eta_{\mathrm{p}}{ }^{2}=.037,90 \% \mathrm{CI}[.001, .11]$ and the interaction between US valence, instruction condition and age group, $F(1,110)=8.95, p=$ $.003, \eta_{\mathrm{p}}^{2}=.075,90 \%$ CI $[.015, .16]$ were also significant. These last four effects are less important from a theoretical point of view.

Insert Figure 1 about here

We assessed the interaction between US valence and time of measurement separately for each type of instructions. These analyses revealed a significant EC effect for standard instructions, $F(1,55)=66.1, p<.001, \eta_{\mathrm{p}}{ }^{2}=.546,90 \% \mathrm{CI}[.39, .65]$, and a significant reversed EC effect for reversal instructions, $F(1,55)=4.96, p=.030, \eta_{\mathrm{p}}{ }^{2}=.083,90 \% \mathrm{CI}$ $[.004, .21]$. As can be seen by comparing the partial $\eta^{2}$, the magnitude of the regular EC effect found for standard instructions was more than six times larger than the reversed effect found for reversal instructions.

To decompose the four-way interaction, we conducted separate analyses for each type of instructions. There was a three-way interaction between US valence, time of measurement and age group for standard instructions, $F(1,55)=9.13, p=.004, \eta_{\mathrm{p}}{ }^{2}=.142,90 \%$ CI $[.029$, 
.28], indicating that the EC effect was moderated by age. The effect was significant in children, $F(1,28)=14.7, p<.001, \eta_{\mathrm{p}}^{2}=.344,90 \% \mathrm{CI}[.11, .52]$, and in adults, $F(1,28)=$ $84.2, p<.001, \eta_{\mathrm{p}}^{2}=.757,90 \%$ CI $[.59, .82]$, however its magnitude was more than two time smaller in children. By contrast, the three way interaction was not significant for reversal instructions, $F(1,55)=0.07, p=.794, \eta_{\mathrm{p}}^{2}=.001,90 \% \mathrm{CI}[0, .049]$. Hence age group failed to significantly moderate the reversed EC effect found with reversal instructions.

Finally, exploratory analyses examined the correlation between age in days and an index of EC (the difference between attitude change for positively and negatively paired CS) among children. It was neither significant for standard instructions, $r(27)=-.051, p=.79$, $95 \%$ CI $[-.41, .32]$ nor for reversal instructions, $r(26)=-.289, p=.136,95 \%$ CI $[-.60, .094]$.

\section{Estimates of controllable and uncontrollable processes}

Insert Table 2 about here

Response frequencies at the dichotomous evaluation task are given in Table 2 . We used multiTree (Moshagen, 2010) to test whether these observed frequencies differ from the frequencies predicted by a model containing one c-, one u-, and one r-parameter per age group. The model fitted the data well, $G^{2}(2)=2.09, p=.351$. As can be seen in Figure 2, in children, the estimate of the $c$-parameter was $c_{\text {children }}=.20$, indicating that controllable valence transfer processes accounted for $20 \%$ of the CS evaluations. The $u$-parameter's estimate was $u_{\text {children }}=.11$, indicating that uncontrollable valence transfer processes accounted for $9 \%$ (i.e., the product of the converse probability of the $c$ - parameter and of the $u$ - 
parameter) of the CS evaluations. The $r$-parameter's estimate was $r_{\text {children }}=.53$. This indicates that among remaining trials in which there was no valence transfer, children responded pleasant in $53 \%$ of the cases (and unpleasant on $47 \%$ of the cases). The estimates of the $c_{\text {children, }} \Delta G^{2}(1)=28.7, p<.001$, and the $u_{\text {children, }} \Delta G^{2}(1)=5.85, p<.015$, parameters differed significantly from zero demonstrating that both controllable and uncontrollable valence transfer processes contributed to CS evaluations and there was no significant response bias as the $r$-parameter did not differ from chance level (i.e., .5), $\Delta G^{2}(1)=0.94, p=.331$..

Insert Figure 2 about here

In adults, the parameter estimates were $c_{\text {adults }}=.64, u_{\text {adults }}=.44$, and $r_{\text {adults }}=.53$. Hence, controllable valence transfer accounted for $64 \%$ of the CS evaluations, uncontrollable valence transfer for $16 \%$ and when there was no valence transfer, adults responded pleasant in $53 \%$ of the cases. As in children, the estimate of the $c_{\text {adults, }} \Delta G^{2}(1)=316, p<.001$, and $u_{\text {adults }}, \Delta \mathrm{G}^{2}$ $=29.7, p<.001$, parameters differed significantly from zero and $r_{\text {adults }}$ did not differ from chance level, $\Delta G^{2}(1)=0.22, p=.639$. Hence, controllable and uncontrollable valence transfer processes contributed to CS evaluations in adults as well.

Next, we tested whether parameter estimates differed as a function of age group. We found that the estimation of the $c$-parameter, $\Delta G^{2}(1)=83.7, p<.001$ as well as of the $u$ parameter, $\Delta G^{2}(1)=12.6, p<.001$, were significantly weaker in children than in adults while the $r$-parameter's estimation did not differ as a function of age group, $\Delta G^{2}(1)=0.01, p=.935$. 
A last series of exploratory analyses tested whether parameter estimates differed as a function of children's school $\operatorname{grade}^{3}\left(^{\text {nd }}\right.$ grade, $\mathrm{n}=22, M_{a g e}=7.68, S D_{a g e}=0.37$ vs. $3^{\text {rd }}$ grade, $\mathrm{n}=17 ; M_{\text {age }}=8.60, S D_{\text {age }}=0.24$ vs. $4^{\text {th }}$ grade, $\left.\mathrm{n}=18 ; M_{\text {age }}=9.88, S D_{\text {age }}=0.46\right)$. The model containing one $c$-, one $u$-, and one $r$-parameter per school grade fitted the data well, $G^{2}(3)=$ $1.64, p=.650$. The estimates of the $c$-parameters were $c_{2 \text { nd grade }}=.16,95 \% \mathrm{CI}[.04, .27], c_{3 \mathrm{rd}}$ grade $=.11,95 \%$ CI $[-.03, .24]$, and $c_{4 \text { th grade }}=.37,95 \%$ CI $[.24, .49]$. The $c$-parameter estimate was larger for $4^{\text {th }}$ grade than for $2^{\text {nd }}$ grade, $\Delta G^{2}(1)=5.51, p=.019$, and $3^{\text {rd }}$ grade children, $\Delta G^{2}(1)=7.58, p=.006$. There was no difference between $2^{\text {nd }}$ and $3^{\text {rd }}$ grade children, $\Delta G^{2}(1)$ $=0.35, p=.557$. These results suggest that controllable valence transfer processes are stronger in older children. The estimates of the $u$-parameters were $u_{2 \text { nd grade }}=.19,95 \%$ CI [.04, $.33], u_{3 \mathrm{rd} \text { grade }}=.05,95 \% \mathrm{CI}[-.10, .20]$ and $u_{4 \text { th grade }}=.05,95 \% \mathrm{CI}[-.14, .25]$. These estimates did not differ significantly as a function of school grade. The estimates of the $r$-parameters were $r_{2 \text { nd grade }}=.53,95 \%$ CI $[.44, .62], r_{3 \text { rd grade }}=.55,95 \%$ CI $[.47, .63]$ and $r_{4 \text { th grade }}=.48,95 \%$ CI $[.38, .59]$. Again, there was no difference between school grades.

\section{Discussion}

The current experiment provided an initial insight into the cognitive processes underlying EC in children by comparing controllable and uncontrollable valence transfer processes in children aged 7 to 11 and young adults in a single experimental paradigm. We found an EC effect in both children and young adults when standard instructions were given. However, its magnitude was smaller in children. When reversal instructions were given, participants were able to take them into account as evidenced by a reversed EC effect which was not significantly moderated by age group. This indicates that children had no specific difficulty in understanding these instructions. Overall, the regular EC effect found with standard instructions was larger than the reversed EC effect found with reversal instructions 
which may indicate that EC is not sustained exclusively by controllable processes. As comparisons between tasks remain ambiguous regarding the cognitive processes involved (Jacoby, 1991), we relied on a multinomial processing tree model to gain insight into the processes underlying valence transfer (Hütter \& Sweldens, 2018).

Our results provided the first evidence suggesting that both controllable and uncontrollable processes are involved in valence transfer in children. In adults, we found that both types of processes were present as well and thereby replicated the results of Hütter and Sweldens (2018). As predicted, controllable processes were weaker in children than in adults and exploratory analyses suggest that they were weaker in younger children than in older ones. Our results thus show that middle-aged children are already able to use regularities between neutral and affective stimuli to acquire new attitudes via controllable processes and that this ability grows stronger with age. Moreover, they suggest that controllable valence processes are related to more general cognitive control abilities as cognitive control continues developing during adolescence (Sera \& Scott, 2013; Zelazo \& Carlson, 2012). Uncontrollable processes also contributed to valence transfer in children as well as in adults. Interestingly, these processes were weaker in children. This result challenges the assumption that if any automatic processes are involved in EC, they should be fully functional by an early age (Hofmann et al., 2010). It rather suggests that the uncontrollable processes captured by the multinomial processing tree model are processes that are gradually automatized as they strengthen between middle childhood and adulthood (Cleeremans \& Jiménez, 2002).

A potential ambiguity in the interpretation of our results comes from the fact that standard and reversal instructions were given before the conditioning. Participants may thus have exerted control during attitude acquisition (i.e., during pairings encoding) or during attitude expression (i.e., when asked to evaluate CS) (Balas et al., 2014). However, previous 
studies showed that the $c$-parameter was sensitive to experimental manipulations implemented at learning. Moreover, control was not impaired in a within-participants variant of the paradigm in which it is more difficult to implement control during attitude expression because participants evaluate CS from the standard and the reversal conditioning blocks at the same time (Hütter \& Sweldens, 2018). These findings suggest that control is mainly exerted during attitude acquisition at least in adults. It is still possible that children and adults exert control in different ways. In this regard, previous studies showed that preschoolers experienced difficulty with intentionally engaging cognitive control in advance, before the critical event occurs on the basis of explicit predictive cues and rely foremost on reactive control (e.g., Braver et al., 2007 ; Munakata et al., 2012). However, children aged 7 and over (as in the present study) are able to use proactive control much better (Lorsbach \& Reimer, 2008; 2010; Polizzotto et al., 2018) and should thus be able to exert control during attitude acquisition. An interesting perspective for further research would be to examine controllable processes in children of different ages and to examine whether control strategies vary as a function of their age.

As in other processes dissociation approaches (Jacoby, 1991), we estimated the $c$ and $u$-parameters under the assumption that the contribution of both processes to CS evaluations is invariant across instruction conditions. As following reversal instructions may be more difficult, it is plausible that participants exerted more control under reversal instructions (Botvinick et al. 2001). If this was the case, controllable processes could be overestimated and uncontrollable process underestimated because the model would treat CS that acquired US valence via uncontrollable processes in the standard condition as if transfer was due to controllable processes (see Hütter \& Sweldens, 2018 for a more detailed discussion of possible effects of violation of the invariance assumption). Furthermore, if this tendency was more pronounced in children controllable processes could be more overestimated and 
uncontrollable processes more underestimated in children as compared to adults. However, our finding that the $u$-parameter is smaller in children is congruent with previous findings that EC effect size is lower in children in incidental EC paradigm in which controllable transfer is presumably less implemented.

In sum, the current study suggests that children aged 7-11 years are already able to use the co-occurrences between neutral and affective stimuli intentionally to acquire new attitudes and that this ability grows stronger with age. Co-occurrences also led to uncontrollable attitude acquisition, although to a lesser extent than in adults. These results have substantial implications. On a methodological level, they show that multinomial processing tree modeling is a valuable tool to further examine changes in mechanisms underlying attitude formation in children. On a practical level, they suggest that advertisements using emotional pictures can influence children in uncontrollable ways and threaten their freedom of choice. On a theoretical level, they provide the first evidence suggesting that some of the processes involved in attitude acquisition through EC gradually automatize. 


\section{Footnotes}

1. The selected pictures had neither too violent nor sexual content and had been pretested on a small sample of children who did not take part in the study.

2. In line with the recommendations of Lakens (2013), we reported 90\% CIs around the effect size for ANOVAs so that the CIs exclude zero when an effect is significant at an alpha level of $\alpha=.05$. We reported 95\% CIs in other cases.

3. As instruction condition was manipulated between-participants, we could not compute individual parameter estimates. We thus compared the parameter estimates as a function of children school grades rather than as a function of their age in days. 


\section{Acknowledgment}

We thank Nabil Abi Abdallah for his help with data collection.

\section{Declaration of Conflicting Interest}

The authors declared no conflicts of interest with respect to the authorship or the publication of this article. 


\section{References}

Balas, R., \& Gawronski, B. (2012). On the intentional control of conditioned evaluative responses. Learning and Motivation, 43, 89-98.

Bargh, J. A. (1992). The ecology of automaticity: Toward establishing the conditions needed to produce automatic processing effects. The American journal of psychology, 181-199.

Bargh, J. A., Schwader, K. L., Hailey, S. E., Dyer, R. L., \& Boothby, E. J. (2012). Automaticity in social-cognitive processes. Trends in cognitive sciences, 16, 593-605.

Beckers, T., De Vicq, P., \& Baeyens, F. (2009). Evaluative conditioning is insensitive to blocking. Psychologica Belgica, 49, 41-57.

Botvinick, M. M., Braver, T. S., Barch, D. M., Carter, C. S., \& Cohen, J. D. (2001). Conflict monitoring and cognitive control. Psychological review, 108, 624.

Braver, T. S., Gray, J. R., \& Burgess, G. C. (2007). Explaining the many varieties of working memory variation: Dual mechanisms of cognitive control. Variation in working memory, $75,106$.

Charlesworth, T. E., Kurdi, B., \& Banaji, M. R. (2020). Children's implicit attitude acquisition: Evaluative statements succeed, repeated pairings fail. Developmental science, 23, e12911.

Chevalier, N. (2015). The development of executive function: Toward more optimal coordination of control with age. Child Development Perspectives, 9, 239-244. https://doi.org/10.1111/cdep.12138

Chevalier, N., \& Blaye, A. (in press). Developing cognitive control and flexible adaptation during childhood. In O. Houdé \& G. Borst (Eds.), The Cambridge Handbook of Cognitive development. Cambridge: Cambridge University Press.

Cleeremans, A., \& Jiménez, L. (2002). Implicit learning and consciousness: A graded, dynamic perspective. Implicit learning and consciousness, 2002, 1-40. 
Corneille, O., Mierop, A., Stahl, C., \& Hütter, M. (2019). Evidence suggestive of uncontrollable attitude acquisition replicates in an instructions-based evaluative conditioning paradigm: Implications for associative attitude acquisition. Journal of Experimental Social Psychology, 85, 103841.

Corneille, O., \& Stahl, C. (2019). Associative attitude learning: A closer look at evidence and how it relates to attitude models. Personality and Social Psychology Review, 23, 161189.

De Houwer, J. (2007). A conceptual and theoretical analysis of evaluative conditioning. The Spanish journal of psychology, 10, 230-241.

Field, A. P. (2006). I don't like it because it eats sprouts: Conditioning preferences in children. Behavior Research and Therapy, 44, 439-455. doi:10.1016/j.brat.2005.03.006

Gawronski, B., Balas, R., \& Creighton, L. A. (2014). Can the formation of conditioned attitudes be intentionally controlled? Personality and Social Psychology Bulletin, 40, 419-432.

Gawronski, B., \& Bodenhausen, G. V. (2014). Implicit and explicit evaluation: A brief review of the associative-propositional evaluation model. Social and Personality Psychology Compass, 8, 448-462.

Gawronski, B., Mitchell, D. G., \& Balas, R. (2015). Is evaluative conditioning really uncontrollable? A comparative test of three emotion-focused strategies to prevent the acquisition of conditioned preferences. Emotion, 15, 556-568.

Gonthier, C., Ambrosi, S., \& Blaye, A. (2021). Learning-based before intentional cognitive control: Developmental evidence for a dissociation between implicit and explicit control. Journal of Experimental Psychology: Learning, Memory, and Cognition. https://doi.org/10.1037/xlm0001005 
Gonthier, C., Zira, M., Colé, P., \& Blaye, A. (2019). Evidencing the developmental shift from reactive to proactive control in early childhood and its relationship to working memory. Journal of experimental child psychology, 177, 1-16.

Halbeisen, G., Schneider, M., \& Walther, E. (2020). Liked for their looks: evaluative conditioning and the generalisation of conditioned attitudes in early childhood. Cognition and Emotion, 1-12.

Halbeisen, G., Walther, E., \& Schneider, M. (2017). Evaluative conditioning and the development of attitudes in early childhood. Child development, 88, 1536-1543.

Hofmann, W., De Houwer, J., Perugini, M., Baeyens, F., \& Crombez, G. (2010). Evaluative conditioning in humans: a meta-analysis. Psychological Bulletin, 136, 390-421.

Hollands, G. J., Prestwich, A., \& Marteau, T. M. (2011). Using aversive images to enhance healthy food choices and implicit attitudes: An experimental test of evaluative conditioning. Health Psychology, 30, 195.

Hütter, M., \& Sweldens, S. (2018). Dissociating controllable and uncontrollable effects of affective stimuli on attitudes and consumption. Journal of Consumer Research, 45, 320349.

Hütter, M., Sweldens, S., Stahl, C., Unkelbach, C., \& Klauer, K. C. (2012). Dissociating contingency awareness and conditioned attitudes: Evidence of contingency-unaware evaluative conditioning. Journal of Experimental Psychology: General, 141, 539.

Jacoby, L. L. (1991). A process dissociation framework: Separating automatic from intentional uses of memory. Journal of Memory and Language, 30, 513-541.

Kail, R. (1988). Developmental functions for speeds of cognitive processes. Journal of Experimental Child Psychology, 45, 339-364.

Lakens, D. (2013). Calculating and reporting effect sizes to facilitate cumulative science: A practical primer for t-tests and ANOVAs. Frontiers in Psychology, 4, 1-12. 
Lang, P. J. ,Bradley, M. M., \& Cuthbert, B. N.(2008). International affective picture system (IAPS): Affective ratings of pictures and instruction manual. Technical Report A-8. University of Florida; Gainesville, FL.

Lorsbach, T. C., \& Reimer, J. F. (2008). Context processing and cognitive control in children and young adults. The Journal of genetic psychology, 169, 34-50.

Lorsbach, T. C., \& Reimer, J. F. (2010). Developmental differences in cognitive control: Goal representation and maintenance during a continuous performance task. Journal of Cognition and Development, 11, 185-216.

Lundqvist, D., Flykt, A., \& Öhman, A. (1998). The Karolinska directed emotional faces (KDEF). CD ROM from Department of Clinical Neuroscience, Psychology section, Karolinska Institutet, 91, 630.

McLaren, I. P., Forrest, C. L. D., McLaren, R. P., Jones, F. W., Aitken, M. R. F., \& Mackintosh, N. J. (2014). Associations and propositions: The case for a dual-process account of learning in humans. Neurobiology of learning and memory, 108, 185-195.

Miller, E. K., \& Cohen, J. D. (2001). An integrative theory of prefrontal cortex function. Annual Review of Neuroscience, 24, 167-202. https://doi.org/10.1146/annurev.neuro.24.1.167

Mitchell, C. J., De Houwer, J., \& Lovibond, P. F. (2009). The propositional nature of human associative learning. Behavioral and Brain Sciences, 32, 183-246.

Moshagen, M. (2010). multiTree: A computer program for the analysis of multinomial processing tree models. Behavior Research Methods, 42, 42-54.

Munakata, Y., Snyder, H. R., \& Chatham, C. H. (2012). Developing cognitive control: Three key transitions. Current directions in psychological science, 21, 71-77. 
Olson, M. A., \& Fazio, R. H. (2006). Reducing automatically activated racial prejudice through implicit evaluative conditioning. Personality and Social Psychology Bulletin, 32, 421-433.

Polizzotto, N. R., Hill-Jarrett, T., Walker, C., \& Cho, R. Y. (2018). Normal development of context processing using the AXCPT paradigm. Plos one, 13, https://doi.org/10.1371/journal.pone.0197812.

Rutland, A., Cameron, L., Milne, A., \& McGeorge, P. (2005). Social norms and selfpresentation: Children's implicit and explicit intergroup attitudes. Child development, 76, 451-466.

Sera, M. D., \& Scott, N. (2013, October). Development of Cognitive Control: Where are We and What's Next? In Minnesota Symposia on Child Psychology: Developing Cognitive Control Processes: Mechanisms, Implications, and Interventions (Vol. 37, pp. 231-245). Hoboken, NJ, USA: John Wiley \& Sons, Inc.

Spelke, E. S., \& Kinzler, K. D. (2007). Core knowledge. Developmental science, 10, 89-96.

Stuart, E. W., Shimp, T. A., \& Engle, R. W. (1987). Classical conditioning of consumer attitudes: Four experiments in an advertising context. Journal of consumer research, 14, 334-349.

Sweldens, S., Corneille, O., \& Yzerbyt, V. Y. (2014). The role of awareness in attitude formation through evaluative conditioning. Personality and Social Psychology Review, $18,187-209$.

Treisman, A., Vieira, A., \& Hayes, A. (1992). Automaticity and preattentive processing. The American journal of psychology, 341-362.

Tzelgov, J. (1997). Automatic but conscious: That is how we act most of the time. The automaticity of everyday life: Advances in social cognition, 10, 217-230. 
Waroquier, L. (2021). Age-related changes in controllable and uncontrollable processes underlying evaluative conditioning: a comparison between 7-11 year old children and young adults. Retrieved from osf.io/8yskg

Waroquier, L., Abadie, M., Dienes, Z. (2020) Distinguishing the role of conscious and unconscious knowledge in Evaluative Conditioning. Cognition, 205, 104460. https://doi.org/10.1016/j.cognition.2020.104460.

Wimmer, M. C., \& Howe, M. L. (2009). The development of automatic associative processes and children's false memories. Journal of Experimental Child Psychology, 104, 447-465.

Zanolie, K., \& Crone, E. A. (2018). Development of Cognitive Control across Childhood and Adolescence. In Stevens' Handbook of Experimental Psychology and Cognitive Neuroscience (pp. 1-24). https://doi.org/10.1002/9781119170174.epcn405

Zelazo, P. D., \& Carlson, S. M. (2012). Hot and cool executive function in childhood and adolescence: Development and plasticity. Child development perspectives, 6, 354-360. 


\section{Figures}

\section{Figure 1.}

Mean CS evaluation as a function of US valence, time of measurement, instruction condition and age group.
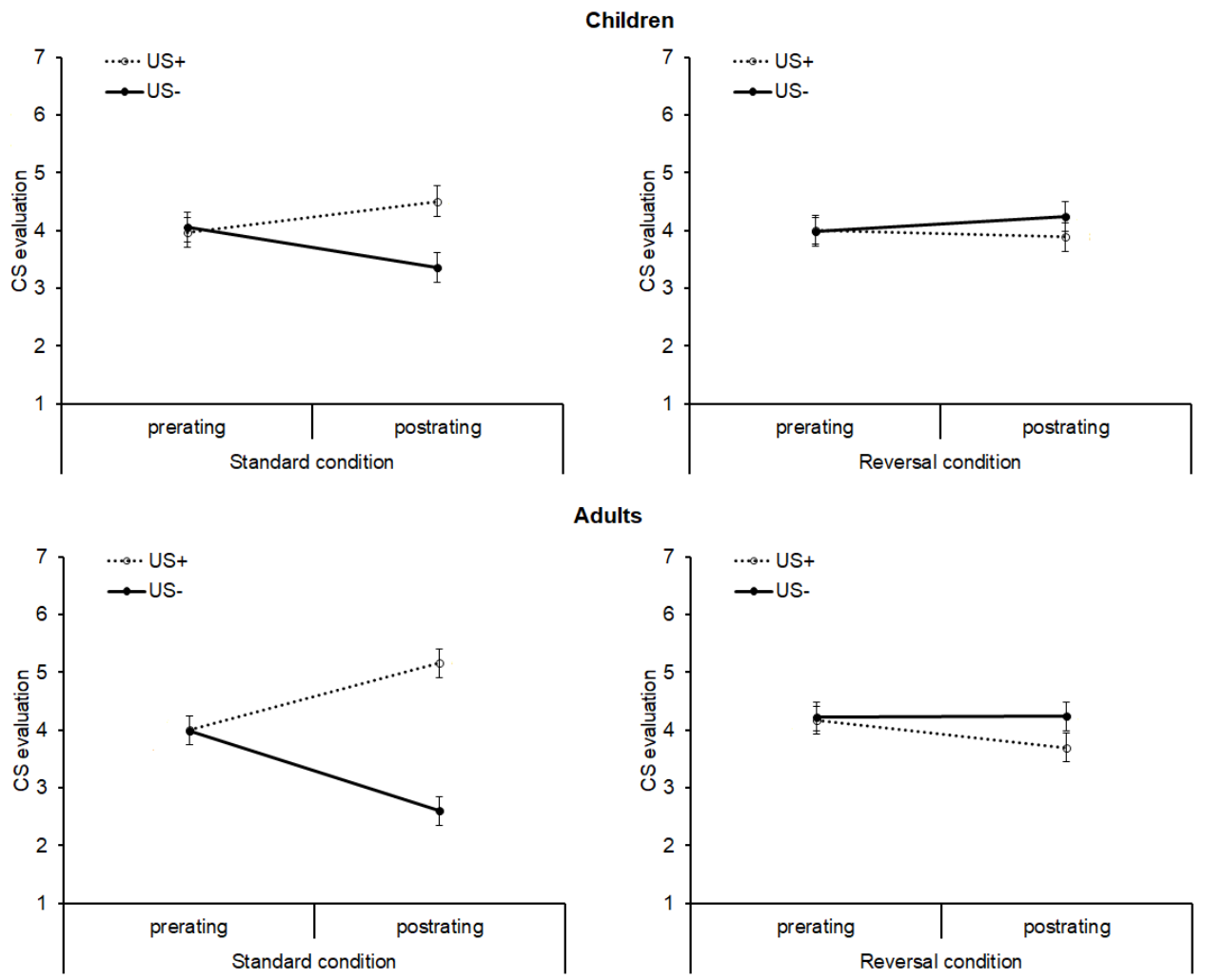

Adults

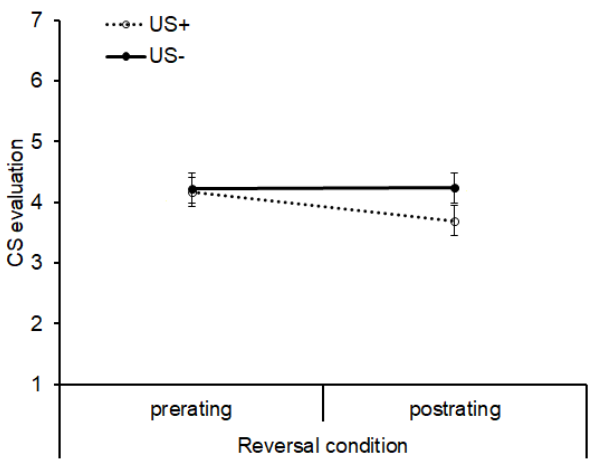

Note. $\mathrm{CS}=$ conditioned stimuli, $\mathrm{US}+=$ positive unconditioned stimulus, $\mathrm{US}-=$ negative unconditioned stimulus. Error bars represent $95 \%$ confidence intervals. 


\section{Figure 2.}

Parameter estimates as a function of age group.

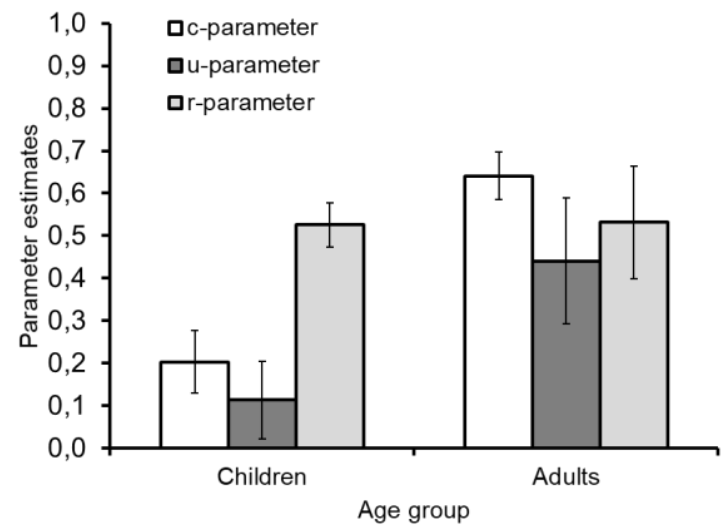

Note. The $c$-parameter reflects controllable valence transfer; $u$-parameter reflects uncontrollable valence transfer; $r$-parameter reflects positive responses based on nonsystematic processes. Error bars represent $95 \%$ confidence intervals. 


\section{Tables}

Table 1.

Power Analyses for Hypothesis Tests

Significance of $c$ and $u$-parameter (test against zero)

\begin{tabular}{lccc}
\hline Age group & Parameter & Cohen's w & Power $(1-\beta)$ \\
\hline adults & $c$ & 0.48 & 1 \\
children & $c$ & 0.14 & 1 \\
adults & $u$ & 0.15 & 1 \\
children & $u$ & 0.07 & 0.68 \\
\hline
\end{tabular}

$\frac{u}{\text { Parameter comparisons across age groups }}$

\begin{tabular}{llcc}
\hline adults vs. children & $c$ & 0.25 & 1 \\
adults vs. children & $u$ & 0.1 & 0.95 \\
\hline
\end{tabular}

Note. $\mathrm{w}=.1$ is considered as a small effect, $\mathrm{w}=.3$ as a medium effect and $\mathrm{w}=.5$ as a large effect (Cohen, 1988). The analyses were based on 1368 observations as there were 12 conditioned stimuli per participant.

Table 2.

Number of CS categorized as pleasant and unpleasant as a function of US valence, instruction condition and age group.

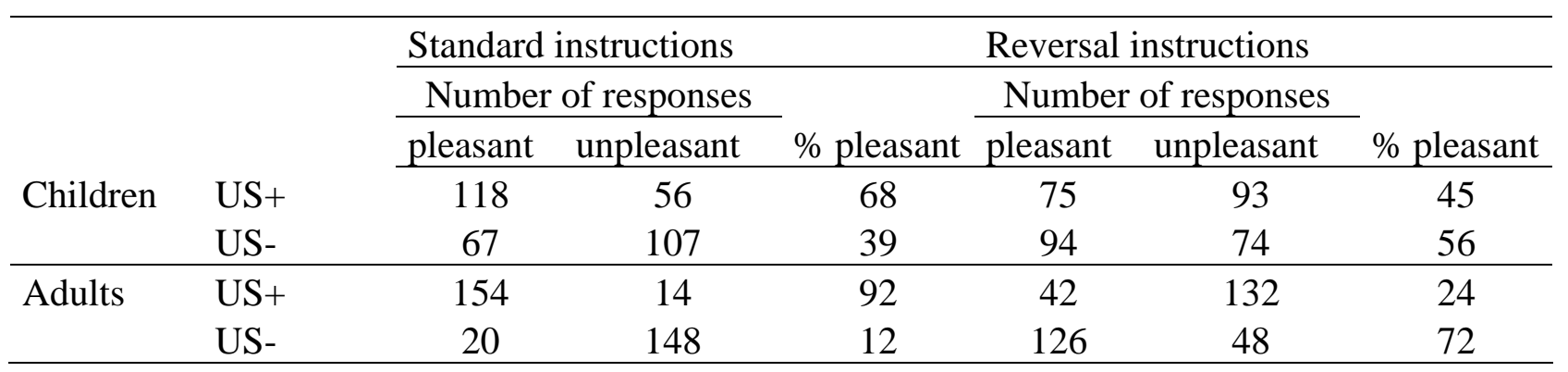

Note. US+ = positive unconditioned stimulus, US- = negative unconditioned stimulus. 